csDMARD therapy but had comparable improvements in PROs at 6 months from initiation.

Acknowledgements: This study is sponsored by Corrona, LLC. The Corrona, LLC. has been supported through contracted subscriptions in the last two years by AbbVie, Amgen, BMS, Crescendo, Eli Lilly and Company, Genentech, GSK, Horizon Pharma USA, Janssen, Momenta Pharmaceuticals, Novartis, Pfizer, Roche and UCB. The design, study conduct, and financial support for the study was provided by AbbVie. AbbVie participated in the interpretation of data, review, and approval of the abstract.

Disclosure of Interest: D. Pappas Grant/research support from: AbbVie, Consultant for: AbbVie, Employee of: Corrona, LLC, J. Griffith Shareholder of: AbbVie, Inc, Employee of: AbbVie, Inc, C. Schlacher Shareholder of: AbbVie, Inc, Employee of: AbbVie, Inc, J. Suboticki Shareholder of: AbbVie, Inc, Employee of: AbbVie, Inc, R. Harrison Employee of: Corrona, LLC, Y. Shan Employee of: Corrona, LLC, C. Karki Employee of: Corrona, LLC, J. Kremer Shareholder of: Corrona, LLC, Grant/research support from: AbbVie, Genentech, Lilly, Novartis, Pfizer, Consultant for: AbbVie, Amgen, BMS, Genentech, Lilly, Regeneron, Sanofi, Pfizer, Employee of: Corrona, LLC

DOI: 10.1136/annrheumdis-2017-eular.1924

\section{FRI0189 SIMILAR EFFICACY AND SAFETY OF BIOSIMILAR CANDIDATE BI 695501 AND ADALIMUMAB ORIGINATOR REFERENCE PRODUCT IN PATIENTS WITH MODERATE TO SEVERE ACTIVE RHEUMATOID ARTHRITIS: 24 WEEK RESULTS FROM A PHASE III CLINICAL STUDY (VOLTAIRE ${ }^{\circledR}$-RA)}

S. Cohen ${ }^{1}$, A. Alonso-Ruiz ${ }^{2}$, P.A. Klimiuk ${ }^{3}$, E. Lee ${ }^{4}$, N. Peter ${ }^{5}$, I. Sonderegger ${ }^{5}$, D. Assudani ${ }^{5} .{ }^{1}$ Metroplex Clinical Research Center, Dallas, United States; ${ }^{2}$ Hospital de Cruces, Barakaldo, Spain; ${ }^{3}$ Medical University of Bialystok and Gabinet Internistyczno-Reumatologiczny, Bialystok, Poland; ${ }^{4}$ Inland

Rheumatology, Upland, United States; ${ }^{5}$ Boehringer Ingelheim, Ingelheim a.R., Germany

Background: PK bioequivalence of BI 695501, a biosimilar candidate, and the adalimumab originator was demonstrated previously (VOLTAIRE ${ }^{\circledR}$-PK: Wynne et al., Expert Opin Investig Drugs 2016;25:1361-70) and led to further clinical development.

Objectives: To demonstrate clinical equivalence of BI 695501 with the adalimumab originator by comparing efficacy, safety and immunogenicity using a clinical model sensitive to detect potential differences between the two biologics. Methods: In this 58-week, multi-national, multicentre, randomised, double-blind, parallel arm Phase III study (NCT02137226), 645 pts (18-80 years) with moderate to severe active RA on stable treatment with methotrexate were randomised to receive US-licensed SC adalimumab originator or BI 695501 40mg Q2W for 24 weeks. At Wk 24, pts on adalimumab originator were re-randomised to continue the adalimumab originator or switch to BI 695501 until Wk 48. Pts on BI 695501 were dummy re-randomised. Co-primary end points were proportion of pts achieving ACR20 at Wks 12 and 24. Equivalence between BI 695501 and the adalimumab originator was demonstrated if the relevant confidence intervals (Cl) for differences in ACR20 response rate at Wks 12 and 24 were within the predefined margins (Wk 12: $90 \% \mathrm{Cl}-12 \%, 15 \%$; Wk 24: $95 \% \mathrm{Cl}-15 \%, 15 \%$ ). The secondary efficacy end point was change from baseline in DAS28-ESR at Wks 12 and 24. Safety and immunogenicity were exploratory objectives. Wk $48 / 58$ data will be reported later.

Results: The co-primary end points of ACR20 response at Wks 12 and 24 were within the pre-defined criteria for equivalence, demonstrating clinical equivalence between $\mathrm{BI} 695501$ and the adalimumab originator (Table 1).

The proportion of pts with treatment-emergent adverse events (TEAE) was similar between the BI 695501 and the adalimumab originator treatment groups (Table 2).

Table 1. Response at Weeks 12 and 24

\begin{tabular}{|c|c|c|c|c|}
\hline \multirow[t]{2}{*}{ ACR, $\%$} & \multicolumn{2}{|c|}{ Week 12} & \multicolumn{2}{|c|}{ Week 24} \\
\hline & $\begin{array}{c}\text { BI } 695501 \\
\mathrm{n}=321\end{array}$ & $\begin{array}{c}\text { Adalimumab } \\
\text { originator } \\
\mathrm{n}=318\end{array}$ & $\begin{array}{c}\text { BI } 695501 \\
n=321\end{array}$ & $\begin{array}{c}\text { Adalimumab } \\
\text { originator } \\
\mathrm{n}=318\end{array}$ \\
\hline ACR20* & 67.0 & 61.1 & 69.0 & 64.5 \\
\hline ACR50 & 29.3 & 31.0 & 36.8 & 36.8 \\
\hline ACR70 & 10.1 & 11.1 & 13.6 & 18.2 \\
\hline $\begin{array}{l}\text { DAS28-ESR } \text {, mean change } \\
\text { from baseline }(95 \% \mathrm{Cl})\end{array}$ & $\begin{array}{c}-2.1 \\
(-2.28,-2.01)\end{array}$ & $\begin{array}{c}-2.0 \\
(-2.18,-1.91)\end{array}$ & $\begin{array}{c}-2.4 \\
(-2.51,-2.21)\end{array}$ & $\begin{array}{c}-2.4 \\
(-2.54,-2.24)\end{array}$ \\
\hline
\end{tabular}

*Week 12 risk difference (RD) and $90 \% \mathrm{Cl}$ for $\mathrm{Bl} 695501$-adalimumab originator are $5.9 \%$ and $90 \% \mathrm{Cl}(-0.9 \%, 12.7 \%)$; \# Week $24: \mathrm{RD}$ and $95 \% \mathrm{Cl}$ are $4.5 \%$ and $(-3.4 \%, 12.5 \%)$.

Table 2. Overview of TEAEs up to Week 24

\begin{tabular}{lcc}
\hline Pts, $n(\%)$ & BI $695501(n=324)$ & Adalimumab originator $(n=321)$ \\
\hline$\geq 1$ TEAE & $138(42.6)$ & $148(46.1)$ \\
$\geq 1$ TEAE related to trial drug & $36(11.1)$ & $44(13.7)$ \\
$\geq 1$ Non-serious TEAE & $135(41.7)$ & $141(43.9)$ \\
$\geq 1$ serious TEAE & $12(3.7)$ & $18(5.6)$ \\
$\geq 1$ serious TEAE related to trial drug & $1(0.3)$ & $5(1.6)$ \\
A TEAE leading to trial drug discontinuation & $8(2.5)$ & $11(3.4)$ \\
A TEAE leading to death & $0(0.0)$ & $0(0.0)$ \\
\hline
\end{tabular}

Rates of serious AEs and discontinuation due to TEAEs were similar across the groups. No deaths were reported during the study. Similar frequencies of pts tested positive for anti-drug antibodies (BI 695501 43.2\%; adalimumab originator 47.8\%), and neutralising antibodies (BI 695501 16.0\%; adalimumab originator $20.6 \%$ ) in both groups at Week 24.

Conclusions: This study in pts with RA demonstrated that BI 695501 and the adalimumab originator are highly similar in terms of efficacy, safety and immunogenicity. Disclosure of Interest: S. Cohen Grant/research support from: Amgen, Boehringher Ingelheim, Coherus, Pfizer, Consultant for: Amgen, Boehringher Ingelheim, Celltrion, Merck, Pfizer, Sandoz, A. Alonso-Ruiz: None declared, P. Klimiuk: None declared, E. Lee: None declared, N. Peter Employee of: Boehringer Ingelheim, I. Sonderegger Employee of: Boehringer Ingelheim, D. Assudani Employee of: Boehringer Ingelheim

DOI: 10.1136/annrheumdis-2017-eular.3405

\section{FRI0190 CLINICAL OUTCOMES FROM A NATIONWIDE NON-MEDICAL SWITCH FROM ORIGINATOR TO BIOSIMILAR ETANERCEPT IN PATIENTS WITH INFLAMMATORY ARTHRITIS AFTER 5 MONTHS FOLLOW-UP. RESULTS FROM THE DANBIO REGISTRY}

B. Glintborg, I.J. Sørensen, A.G. Loft, J. Esbesen, H. Lindegaard, D.V. Jensen,

K. Danebod, S. Dieperink, O. Hendricks, I.M.J. Hansen, A. Linauskas,

S. Kristensen, L.S. Andersen, M. Hossein, H. Nordin, B.L. Andersen,

S. Chrysidis, J.L. Raun, N. Manilo, J. Grydehøj, E.B. Dalgaard, D.D. Pedersen,

N.S. Krogh, M.L. Hetland. The DANBIO registry and the Danish Departments of Rheumatology, Copenhagen, Denmark

Background: In Denmark, biological drugs are provided free by the hospitals to the patients via a tax-based system. In 2015 a non-medical switch from originator infliximab to CT-P13 was conducted (1). According to national guidelines in April 2016, a non-medical switch from originator (ETA, Enbre ${ }^{\circledR} 50 \mathrm{mg} /$ week) to biosimilar etanercept (SB4, Benepali ${ }^{\circledR}$ ) was dictated when SB4 was marketed, including patients with inflammatory rheumatic diseases treated in routine care. Objectives: To investigate 3 months' disease activity and 5 months' treatment withdrawal in ETA-treated patients (pts) with rheumatoid arthritis (RA), psoriatic arthritis (PsA) and axial spondyloarthrits (SpA), who were switched to SB4 and monitored prospectively in the DANBIO registry.

Methods: Pts with RA/PsA/SpA followed in DANBIO since start of first bDMARD were included. Disease activity at 3 months before switch (pre-switch), at the switch and after 3 months (post-switch) and changes over time ( $\Delta$ pre-switch and $\triangle$ post-switch) were calculated. Disease flare was defined as $\triangle D A S 28 \geq 1.2$ (RA/PsA) or $\triangle \mathrm{ASDAS} \geq 1.3(\mathrm{SpA})$. Factors associated with withdrawal (gender/ age/diagnosis/bDMARD-treatment-no/comedication methotrexate/baseline CRP/ patient's global score) were explored by multivariable Cox regression analysis. Results: In total, 1548 switch pts were identified (891 RA, 335 PsA, 322 SpA). $60 \%$ were women, age (median (IQR) 56 (44-65) yrs)). Prior ETA treatment duration was $5.2(3.2-8.0)$ yrs. ETA was the first biological treatment in $49 \%$, and the second in $33 \%$ of pts. Concomitant MTX was given in $60 \%(\mathrm{RA}) / 49 \%$ (PsA) $/ 15 \%$ (SpA). Median follow-up time was 154 (110-178) days.

Disease activity remained largely unchanged 3 months prior to vs. after the switch (Table). The proportion of patients with disease flare pre-/post switch was $8 \% / 13 \%$ (RA), $9 \% / 13 \%$ (PsA), $5 \% / 5 \%$ (SpA).

Overall, 129 pts (9\%) stopped SB4 treatment during 5 months' follow-up (Table). Prior ETA treatment duration in these patients was $4.5(2.7-7.1)$ years.

Higher patient's global score (HR $1.12 / \mathrm{cm}, 95 \% \mathrm{Cl}(1.05-1.21), \mathrm{p}=0.002)$ and no concomitant methotrexate (HR $2.28(1.48-3.52), p<0.001)$ at baseline were associated with withdrawal.

\begin{tabular}{|c|c|c|c|c|c|c|}
\hline & \multicolumn{3}{|c|}{ Disease activity, median(IQR) } & \multicolumn{2}{|c|}{ Changes, median(IQR) } & \multirow[t]{2}{*}{$\mathrm{P} *^{*}$} \\
\hline & pre-switch & switch & post-switch & $\Delta$ pre-switch & $\Delta$ post-switch & \\
\hline \multicolumn{7}{|l|}{$R A, n=891$} \\
\hline DAS28 & $2.1(1.7-2.9)$ & $2.1(1.6-2.9)$ & $2.2(1.6-3.1)$ & $0.0(-0.4-0.5)$ & $0.0(-0.4-0.5)$ & 0.2 \\
\hline HAQ & $0.6(0.2-1.3)$ & $0.8(0.1-1.3)$ & $0.8(0.3-1.3)$ & $0.0(-0.1-0.1)$ & $0.0(-0.1-0.1)$ & 0.7 \\
\hline CRP, mg/l & $3(1-7)$ & $2(1-6)$ & $3(1-6)$ & $0(-2-1)$ & $0(-1-1)$ & 0.02 \\
\hline VAS global, mm & $30(13-57)$ & $28(13-55)$ & $31(11-62)$ & $0(-11-9)$ & $0(-9-11)$ & 0.1 \\
\hline \multicolumn{7}{|l|}{ PsA, $n=335$} \\
\hline DAS28 & $2.0(1.5-2.6)$ & $2.0(1.6-2.8)$ & $2.1(1.5-3.0)$ & $0.0(-0.2-0.5)$ & $0.0(-0.6-0.5)$ & 0.7 \\
\hline $\mathrm{HAQ}$ & $0.5(0.1-1.1)$ & $0.5(0.0-1.1)$ & $0.5(0.1-1.1)$ & $0.0(-0.1-0.1)$ & $0.0(-0.1-0.1)$ & 0.7 \\
\hline CRP, $\mathrm{mg} / \mathrm{l}$ & $2(1-4)$ & $2(1-4)$ & $2(1-4)$ & $0(-2-1)$ & $0(-1-1)$ & 0.04 \\
\hline VAS global, mm & $31(12-58)$ & $30(13-54)$ & $32(13-59)$ & $0(-9-7)$ & $0(-7-12)$ & 0.2 \\
\hline \multicolumn{7}{|l|}{ SpA, $n=322$} \\
\hline BASDAl, $\mathrm{mm}$ & $33(15-51)$ & $27(12-48)$ & $29(16-47)$ & $-1(-7-5)$ & $1(-5-8)$ & 0.03 \\
\hline CRP, $\mathrm{mg} / \mathrm{l}$ & $3(1-6)$ & $3(1-5)$ & $3(1-5)$ & $0(-2-1)$ & $0(-1-1)$ & 0.4 \\
\hline VAS global, $\mathrm{mm}$ & $34(16-59)$ & $30(12-53)$ & $31(15-53)$ & $-1(-12-6)$ & $2(-6-14)$ & 0.04 \\
\hline ASDAS & $2.0(1.3-2.8)$ & $1.9(1.2-2.7)$ & $1.9(1.3-2.7)$ & $-0.1(-0.4-0.2)$ & $0.1(-0.4-0.5)$ & 0.1 \\
\hline \multicolumn{7}{|c|}{ Reasons for withdrawal during $\approx 5$ months follow-up ( $n=129$ ) } \\
\hline Lack & th & (1) & int & 4 & r. & \\
\hline
\end{tabular}

Conclusions: In 1548 patients with inflammatory rheumatic diseases treated with ETA for $>5$ years, disease activity was largely unaffected in the majority of patients 3 months after non-medical switch to SB4 and comparable to the fluctuations observed in the 3 months prior to the switch. Several patients $(\approx 9 \%)$ 
stopped treatment during 5 months follow-up. Higher patient's global score and no use of methotrexate were associated with withdrawal. Longer follow-up will offer additional understanding of the potential efficacy and safety consequences of the non-medical switch.

References:

[1] Glintborg et al. Arthritis Rheumatol. 2016; 68 (suppl 10): Abstract no 951. Acknowledgements: Data analysis was partly financially supported by Biogen. Disclosure of Interest: B. Glintborg Grant/research support from: Abbvie, Biogen, I. Sørensen: None declared, A. G. Loft: None declared, J. Esbesen: None declared, H. Lindegaard: None declared, D. Jensen: None declared, K. Danebod: None declared, S. Dieperink: None declared, O. Hendricks: None declared, I. M. Hansen Grant/research support from: Roche, A. Linauskas: None declared, S. Kristensen: None declared, L. Andersen: None declared, M. Hossein: None declared, H. Nordin: None declared, B. Andersen: None declared, S. Chrysidis: None declared, J. Raun: None declared, N. Manilo: None declared, J. Grydehøj: None declared, E. Dalgaard: None declared, D. Pedersen: None declared, N. Krogh: None declared, M. Hetland Grant/research support from: Orion, BMS, AbbVie, Biogen, Pfizer, MSD, Eli Lilly

DOI: 10.1136/annrheumdis-2017-eular.1703

\section{FRI0191 INCIDENCE OF DISEASE WORSENING IN INFLAMMATORY ARTHRITIS PATIENTS ON LONG-TERM INNOVATOR INFLIXIMAB THERAPY}

A.M. Marrache ${ }^{1}$, E. Psaradellis ${ }^{2}$, J. Vaillancourt ${ }^{2}$, E. Rampakakis ${ }^{2}$, F. Nantel ${ }^{1}$. ${ }^{1}$ Medical Affairs, Janssen Inc., Toronto; ${ }^{2}$ JSS Medical Research, Montreal, Canada

Background: A recent randomized controlled study in a single country reported rates of disease worsening over a one-year follow-up period for innovator infliximab (REMICADE ${ }^{\circledR}$, IFX) and a comparator in various diseases including AS and RA. After a mean duration of treatment of 6.7 years of innovator IFX, rates for disease worsening post-one year follow-up were $39.5 \%$ in AS and $36.7 \%$ in RA ${ }^{1}$. Other such data reporting disease worsening rates are rare.

Objectives: Using data from a longitudinal database, the objective was to determine the incidence of disease worsening in AS and RA patients on long-term therapy with innovator IFX. PsA patients were not included in this study due to low numbers $(n=49)$.

Methods: BioTRAC is an ongoing, prospective registry of inflammatory arthritis patients initiating treatment with infliximab, golimumab or ustekinumab that has been ongoing since 2002 in Canada. We included AS and RA patients who had been on innovator IFX therapy for at least two, four or six years. Disease worsening endpoint was defined as follows: for AS patients; an increase in ASDAS $>1.1$ from baseline and a minimum score of 2.1. For RA patients; an increase in DAS28 $\geq 1.2$ from baseline and a minimum score of 3.2 .

Results: This analysis included a total of 196 AS and 425 RA patients. Among AS patients, $36.1 \%$ were female, $90.8 \%$ were bio-naïve at IFX initiation and $50 \%$ were on concomitant NSAID(s) at the 2-year index. The mean (SD) ASDAS score was 2.17 (1.05). As for the RA patients, $75 \%$ were female, $88.5 \%$ were bio-naïve, and $93 \%$ were on concomitant DMARD(s) while $35 \%$ were on corticosteroids at the 2-year index. The mean (SD) DAS28 ESR and DAS 28 CRP were 3.37 (1.40) and 3.00 (1.24), respectively.

As shown in table 1, the incidence of disease worsening in AS and RA patients on stable IFX for 2-6 years was low and varied from $2.7 \%$ to $11.5 \%$ at the subsequent 12 and 24 months visit.

Table 1. Incidence of disease worsening in AS and RA patients at the 2, 4, and 6-year index

\begin{tabular}{lcccc}
\hline Disease & Outcome & Index date post IFX initiation & \multicolumn{2}{c}{$\begin{array}{c}\text { Disease worsening at } \\
\text { subsequent visits, } \mathrm{n} / \mathrm{N}(\%)\end{array}$} \\
\cline { 3 - 5 } & & & 12 months & 24 months \\
\hline AS & ASDAS & 2 years & $9 / 79(11.4 \%)$ & $6 / 59(10.2 \%)$ \\
& & 4 years & $2 / 42(4.8 \%)$ & $1 / 37(2.7 \%)$ \\
& & 6 years & $1 / 25(4.0 \%)$ & $2 / 18(11.1 \%)$ \\
RA & 2 years & $20 / 184(10.9 \%)$ & $17 / 148(11.5 \%)$ \\
& DAS28 ESR & 4 years & $9 / 121(7.4 \%)$ & $7 / 106(6.7 \%)$ \\
& & 6 years & $8 / 73(11.0 \%)$ & $5 / 47(10.6 \%)$ \\
& & 2 years & $16 / 160(10.0 \%)$ & $11 / 124(8.9 \%)$ \\
& DAS28 CRP & 4 years & $8 / 115(7.0 \%)$ & $6 / 104(5.9 \%)$ \\
& & 6 years & $6 / 80(7.5 \%)$ & $4 / 54(7.4 \%)$ \\
\hline
\end{tabular}

Conclusions: In this prospective longitudinal cohort, patients on long-term innovator IFX therapy show low rates of disease worsening of $2.7 \%$ to $11.5 \%$ at 1 and 2 years in AS and RA. Additional studies may elucidate the true rate of and reasons for disease worsening in rheumatologic populations.

References:

[1] Goll et al. Biosimilar Infliximab (CT-P13) Is Not Inferior to Originator Infliximab: Results from a 52-Week Randomized Switch Trial in Norway. Arthritis Rheum 2016:68(S10). Abstract 19L.

Disclosure of Interest: A. M. Marrache Employee of: Janssen Inc., E. Psaradellis Employee of: JSS Medical Research, J. Vaillancourt Employee of: JSS Medical Research, E. Rampakakis Employee of: JSS Medical Research, F. Nantel Employee of: Janssen Inc.

DOI: 10.1136/annrheumdis-2017-eular.4545

\section{FRI0192 CLINICAL PRACTICE GUIDE FOR THE TREATMENT OF PATIENTS WITH RHEUMATOID ARTHRITIS (RA). SYSTEMATIC REVIEW: IN PATIENTS WITH RA, WHICH IS THE SAFEST THERAPY FOR PATIENTS WITH PREVIOUS CANCER?}

M.B. Nishishinya ${ }^{1}$, C.A. Pereda ${ }^{2}$, P. Diaz del Campo ${ }^{3}$, A. Balsa ${ }^{4}$ on behalf of GUIPCAR, Evidence based Rheumatology Working Group (SER) and GUIPCAR Working Group. ${ }^{1}$ Traumatology Institute Quirón, Barcelona; ${ }^{2}$ Rheumatology, Hospital Mediterraneo, Almeria; ${ }^{3}$ Investigation Unit, Spanish Rheumatology Society; ${ }^{4}$ Rheumatology, Hospital Universitario la Paz, Madrid, Spain

Background: Anti TNF therapy, has been used for the treatment of RA patients for several years. Yet, cancer and infections are among the most serious adverse effects described. Unfortunately, little is known about the effect of anti TNF therapy amongst patients with RA and previous cancer, mainly when synthetic DMARds treatment fails.

Objectives: To review the evidence on the safety of biological therapy in RA patients with previous neoplasia.

Methods: we performed a systematic review through Medline, Cochrane Library, and EMBASE databases. Studies written in English, French and Spanish were considered. Patients 18 years or older, with RA diagnosis (ACR 1987 o ACR/EULAR 2010 criteria), and cancer diagnosis before starting biologic therapy were included. While Systematic reviews, clinical trials and or observational studies with a minimal follow -up of 6 months were considered; case reports or narrative reviews were excluded.

Results: 1077 studies were potentially identified, and 6 cohort studies were finally included, (Aaltonen 2015, Dixon 2010, Phillips 2015, Raaschou 2015, SilvaFernández 2016, Stranfeld 2010). Studies were based on registries of patients with RA treated with DMARds and biological therapy. Registries evaluated between 3.762 and 14.168 patients. The number of patients with documented previous cancer was around 122 to 425 as a whole. Biological therapies evaluated were: IFX, ETN, ADA, RTX, certolizumab pegol, Golimumab, ANAKinRA and synthetic DMARDs. Studies results were organized as anti TNF vs. DMARDs. All studies assessed were cohort trials, SIGN 2+ (Quality Scale). They included solid tumours as breast cancer, lymphoproliferative tumours, skin cancer, neck and brain tumours, as well as in situ uterus cancer.

There was no increment in the risk of incidence of previous cancer in patients treated both with synthetic DMARDs and with anti TNF therapy in all studies assessed.

We point out, that 1 SR (LaForest Divonne 2016) evaluated biological therapy safety in patients with RA. It included 124 trials, while in 27 metanalysis was performed. From these 27, only 3 (Dixon 2010, Mercer 2013 and Strangfeld 2010) where the only studies which assessed risk of recurrence of previous cancer in patients with RA. The RR 0, 77 (IC 95\% 0, 29-2,03), did not exhibit an increment in the risk of cancer in these patients.

Conclusions: - Studies showed no differences in the incidence of previous cancer in patients treated either with synthetic DMARds or with anti TNF. However, we suggest precaution in the use of these therapies, as the real risk in this population is still unknown.

- The final decision of treating or not treating these patients (risk factors, limitations etc.) needs to be performed in accordance with oncologists.

- There is no strong evidence that could identify the real risk of anti TNF therapies in RA patients, with previous cancer.

- The Individual impact risk of different anti-TNF therapies in this population could not be performed due to incomplete data. Yet, there is not real time schedule considering time since previous cancer and the start of anti TNF therapy.

Well design studies with long follow-up periods are needed to answer these questions

Disclosure of Interest: None declared

DOI: 10.1136/annrheumdis-2017-eular.5953

\section{FRI0193 EFFECT OF VALENCY OF ANTI-TNFS ON ELIMINATION MEDIATED BY ANTI-DRUG ANTIBODIES}

\section{J. Silva, A. Nesbitt. UCB Pharma, Slough, United Kingdom}

Background: There are five different anti-TNF biologics: three are bivalent full length (FL) antibodies (adalimumab, golimumab, and infliximab), one a bivalent fusion protein (etanercept), and one a univalent PEGylated Fab' (PF) (certolizumab pegol [CZP]). Administration of such protein biologics can induce anti-drug antibodies (ADAbs), of which the majority are anti-idiotypic antibodies (anti-ID). ${ }^{1}$ The potential cross-linking of bivalent anti-IDs with bivalent biologics can result in the formation of large immune complexes (ICs), which are subsequently cleared by mechanisms using the multiple $\mathrm{Fc}$ domains, thereby resulting in a decrease in the efficacy of the biologic. Since univalent biologics, such as CZP, only have one binding Fab' arm, such large cross-linked anti-ID-mediated ICs are unlikely to form. Therefore, anti-IDs may have a different effect on the elimination and bioavailability of univalent and bivalent biologics in vivo.

Objectives: To determine if the valency of a biologic will affect the in vitro size and in vivo elimination from the plasma of ICs formed with an anti-ID following intravenous (IV) administration to BALB/c mice.

Methods: An anti-ID antibody to CZP was generated and used for subsequent studies to mimic an ADAb response. Univalent PF CZP was reengineered as a bivalent FL humanized IgG1 antibody (similar to adalimumab) to directly 